\title{
A note on the power of money-output causality tests ${ }^{\dagger}$
}

\author{
YIN-Wong Cheung and EIJI FuJII
}

Department of Economics, University of California, Santa Cruz

Department of Economics, Otaru University of Commerce, Japan

efujii@res.otaru-uc.ac.jp

\section{Introduction}

The role of money and its effects on national output have generated a voluminous amount of literature (Blanchard, 1990; Lucas, 1996; Sargent, 1996). Since Friedman and Schwartz (1963) rekindled the research on the effects of money on aggregate output, numerous studies have aimed to characterize and establish the interactions between money and output. Theoretical models are constructed to show that money can affect output via different channels, including unanticipated monetary shocks, real and nominal rigidities, and menu costs. However, the accumulated empirical results, which are derived from different specifications, different sample periods, and data from different countries, still do not give a definite answer to the question of whether money affects output. Also, there are diverse opinions on how money affects output.

Most empirical studies adopt a vector autoregression (VAR) framework or a modified one to analyze the causal relationship between money and output following the two seminal studies by Sims $(1972,1980)$. A basic regression equation has output as the dependent variable and lagged output and money as regressors. The basic specification is often augmented with additional macroeconomic variables as controlling variables. The statistical significance of the lagged money variable is used to evaluate the effects of money. Depending on the choices of sample periods, controlling variables, and data

\footnotetext{
${ }^{\dagger}$ We are grateful to Jonathan Temple (the editor), Menzie Chinn, Mike Dooley, Carl Walsh, and seminar participants of the Western Economic Association $73^{\text {rd }}$ Annual Conference for their comments and suggestions. The usual disclaimer applies.
} 
transformation methods, one can get a wide range of results on the significance of the money variable.

In this study we examine the implications of conditional heteroskedasticity for testing the effects of money on output. The family of autoregressive conditional heteroskedastic $(\mathrm{ARCH})$ processes is the predominant tool to model conditional heteroskedastic behavior in economic time series. Introducing stationary conditional heteroskedasticity to the classical regression framework does not affect the best linear unbiased estimator status of the least squares (LS) estimator. However, as pointed out by Engle (1982), conditional heteroskedasticity will lead to inconsistent standard errors for LS estimates when the set of regressors contains lagged dependent variables. Thus, the LS approach to test for money-output causality, which typically includes lagged output variables as regressors, can lead to misleading inferences in the presence of conditional heteroskedasticity.

In the following sections we verify that the presence of conditional heteroskedasticity can lead to a significant loss in the power of the usual LS test for monetary effects. One possible way to improve upon the LS approach is to pursue the maximum likelihood (ML) technique, which is known to be able to deliver more efficient and precise estimators. In general, more efficient and precise estimators allow more reliable inferences on the significance of the explanatory variables. Using Monte Carlo methods we illustrate that, compared with the usual LS approach, the ML procedure incorporating the ARCH structure has a better power to detect causality in the presence of conditional heteroskedastic errors. While the efficacy of the ARCH-ML method provides a more precise estimation, it should be pointed out that the importance of money depends on both the significance and magnitude of the monetary effect.

Theoretically, the presence of ARCH effects in the usual money-output causation regression can be attributed to uncertainties in monetary policy and output. For instance, the signal/noise approach pioneered by Lucas (1972) shows that imperfect information about money can induce monetary effects on output. Uncertainty in money can be a result of measurement issues, unavoidable policy errors, or authorities' planned randomization. In the presence of imperfect information, output is affected by unexpected changes in money and, subsequently, output volatility is related to, among other factors, monetary volatility. In fact, conditional heteroskedasticity can be generated from the Taylor (1975) model in which the public determines their output decisions according to the perceived policy. When the public infers the monetary policy, via trials and errors, from the observed data, information imperfection can induce persistence variation and $\mathrm{ARCH}$ type effects in output data.

There are other possible reasons for the presence of ARCH effects. For instance the ARCH term can be attributed to missing variables or news 
variables that arrive in a clustering manner. The $\mathrm{ARCH}$ phenomenon is also related to the notion of time deformation (Stock, 1988). When the economic and calendar time scales are not the same, data recorded according to calendar time can exhibit ARCH behavior even when there is no conditional heteroskedasticity under the economic time scale. It seems that there are various channels whereby ARCH may arise in the money-output regression. Thus, if the output (conditional) volatility is not completely captured by money variables and other regressors, we have to control for the ARCH effect in testing for monetary effects.

Of course, the presence or absence of $\mathrm{ARCH}$ is an empirical issue. Existing studies indicate that $\mathrm{ARCH}$ effects are quite common among economic variables. As a preliminary analysis, we examined the time series properties of data on output and money used in this exercise. After controlling for the ARMA dynamics, there is substantial evidence of ARCH effects. In fact, for the sample periods considered, the ARCH effects in output and money data are statistically significant at the $1 \%$ to $10 \%$ levels. Thus, the presence of $\mathrm{ARCH}$ and its effects on money-output causality tests are not merely a theoretical possibility, it is also an empirically relevant issue.

The remainder of the paper is organized as follows. Section II briefly reviews the empirical literature on money-output causality. Section III illustrates the effect of an ARCH error term. It is found that the power of the standard F-test for causality is drastically weakened in the presence of ARCH errors. Compared with the F-test, the ML approach allowing for ARCH effects has better power to detect a causality relationship. Section IV reestimates two money-output regressions reported in Friedman and Kuttner (1993) and Thoma (1994). Conditional heteroskedasticity is found in the regression specifications used in these two studies. Once the ARCH effect is accounted for, we find evidence of money causing output - a result that is contrary to the ones reported in the original studies. In the same section, we also explore the implications of ARCH effects for estimating the magnitude of monetary effects. Some concluding remarks are offered in Section V.

\section{Selective Literature Review}

Comparing the cyclical patterns of the U.S. historical data on money and output, Friedman and Schwartz (1963) provocatively contend the strong effect of money on output. As it is difficult to disentangle cause from effect using correlation patterns alone, Sims (1972) offers a formal procedure to test the hypothesis that money causes output. Sims (1980) further proposes the VAR methodology, which considers the possible effects of variables other than money and output, to analyze the monetary effect. A common regression equation used in the VAR tradition to study the effect of money on output is 


$$
y_{t}=f_{t}+\sum_{i=1}^{p} \gamma_{i} y_{t-i}+\sum_{i=1}^{q} \lambda_{i} m_{t-i}+\sum_{i=1}^{r} \alpha_{i} w_{t-i}+\varepsilon_{t}
$$

where $y_{\mathrm{t}}$ is a measure of output, $m_{\mathrm{t}}$ a measure of money, and $w_{\mathrm{t}}$ a vector of controlling variables. $\gamma_{\mathrm{i}}, \lambda_{\mathrm{i}}$, and $\alpha_{\mathrm{i}}$ are coefficients of the appropriate dimensions, $f_{\mathrm{t}}$ is the trend term, $p, q$, and $r$ are lag order parameters, and $\varepsilon_{\mathrm{t}}$ is the error term.

The evidence of monetary effects depends on, among other things, the choice of variables included in (1), the method used to transform the data, the specification of the trend term, and the sample period under consideration. ${ }^{1}$ For instance, Sims (1972) examines a bivariate system containing only $y_{\mathrm{t}}$ and $m_{\mathrm{t}}$ and reports strong evidence of money causing output. However, the monetary effect vanishes when short-term interest rates are included as a control variable (Sims, 1980; Litterman and Weiss, 1985). Christiano and Ljungqvist (1988) show that monetary effects are found in log-level data but not in first-differenced data. Stock and Watson (1989) offer a detailed study on the implications of trend specifications on causal regression analyses. These authors find that deviations of M1 growth from its linear time trend affect output growth. The reported monetary effect, however, appears not robust to two modifications: a) an extension of the sample period; and b) an alternative choice of the interest rate variable (Friedman and Kuttner, 1992, 1993). ${ }^{2}$

The empirical research on the effect of money expands rapidly in several directions following advances in theories that incorporate imperfect information, nominal rigidities, and menu costs. Sophisticated empirical models have been devised to examine the implications of anticipated and unanticipated (Barro, 1977), positive and negative (Cover, 1992; Thoma, 1994), and large and small monetary shocks (Ravn and Sola, 1996) on output movements. ${ }^{3}$

\footnotetext{
${ }^{1}$ It is noted that the use of equation (1) to infer the causal relationship between money and output is not a universally accepted procedure. For instance, equation (1) can be interpreted in terms of the incremental explanatory power of money. However, for expositional purposes, we follow the 'convention' in the money-output causality literature while realizing the controversy of such an interpretation. See, for example, Granger (1980) for a detailed discussion on issues related to testing for causality in economics.

${ }^{2}$ Krol and Ohanian (1990) report that the finding of Stock and Watson (1989) may be country specific. Using the Stock and Watson framework, these authors find very limited or no evidence of money causing output for Canada, Germany, and Japan.

${ }^{3}$ A variety of asymmetric monetary effects are reported. Barro (1977) reports that unanticipated money shocks affect output while anticipated shocks do not. Cover (1992) categorizes money supply shocks into positive and negative shocks and finds that only negative ones affect output growth. Rhee and Rich (1995) report that the degree of asymmetry between positive and negative money shocks is positively correlated with average inflation. Thoma (1994) finds that the asymmetry between positive and negative money growth becomes significant only if the effects of money are allowed to vary over business cycles. Ravn and Sola (1996) argue that asymmetry exists between large and small money shocks according to the menu-costs hypothesis.
} 
The set of controlling variables has been expanded to include, for example, monetary policy regimes (Bernanke and Mihov, 1998), commodity prices (Sims, 1992), and credit rationing (Galbraith, 1996). Recently, the implications of identifying restrictions on money-output causality test results, a fundamental issue underlying the VAR approach, have been investigated. Cochrane (1998) argues that a reasonable assumption specifying the relative effects of anticipated and unanticipated money should be used to study the effect of money on output. Faust (1998) examines the hypothesis that, for every reasonably identified VAR, the monetary effect accounts for a small share of the forecast error variance of output and finds little support for it.

\section{ARCH Disturbance and Causality Test}

The family of ARCH processes, first proposed by Engle (1982), is a convenient and powerful device to analyze the volatility clustering phenomenon commonly observed in economic time series. For a classical regression model, the introduction of a stationary ARCH error term does not invalidate the Gauss-Markov theorem. The LS estimator is still the best linear unbiased estimator. Asymptotically, however, the ML estimator incorporating the ARCH effect is more efficient than the LS one. Further, if lagged dependent variables are included as regressors, the LS procedure may lead to inconsistent results. The inconsistency arises because of the dependence between ARCH errors and lagged dependent variables. Thus, standard errors computed from the LS routine are not consistent and can give rise to misleading statistical inferences (Engle, 1982, p. 994).

In their study of the causal relationship between consumer and wholesale price indexes, Granger, Robins, and Engle (1984) report that individual parameter estimates from the LS regression and from the ARCH-ML estimation are quite different. Grier and Perry (1993) show that the LS procedure and the ML estimation allowing for $\mathrm{ARCH}$ effects give dramatically different conclusions on the effect of money on interest rates. To gain more insight into the issue, we conducted a Monte Carlo experiment to investigate the possible effects of ARCH disturbances on the size and power of causality tests. The experimental design for the power study is as follows. Two artificial data series are generated according to

$$
\begin{aligned}
z_{t} & =\varphi_{0}+\varphi_{1} z_{t-1}+\varphi_{2} x_{t-1}+v_{t} \\
v_{t} & \sim \operatorname{iidN}(0,1)
\end{aligned}
$$

and 


$$
\begin{gathered}
z_{t}=\varphi_{0}+\varphi_{1} z_{t-1}+\varphi_{2} x_{t-1}+\varepsilon_{t}, \\
\varepsilon_{t \mid t-1} \equiv v_{t} h_{t}^{1 / 2}, h_{t}=\alpha_{0}+\alpha_{1} \varepsilon_{t-1}^{2} .
\end{gathered}
$$

By construction, $x_{\mathrm{t}-1}$ and $\mathrm{v}_{\mathrm{t}}$ are independent and $x_{\mathrm{t}}$ causes $z_{\mathrm{t}}$ if $\varphi_{2} \neq 0$. The hypothesis that $x_{\mathrm{t}}$ does not cause $z_{\mathrm{t}}$ is evaluated by testing if $\varphi_{2}=0$. The main difference between (2) and (3) is that the error term in (2) is the conventional white noise process while the one in (3) follows an $\mathrm{ARCH}(1)$ specification.

To evaluate the impact of ARCH effects on the causality test, we apply the standard F-test, which is commonly used to test for causality, to the data generated by (2) and (3) to test the hypothesis of $\varphi_{2}=0$. The rejection percentages, based on 10,000 replications and a sample size of 300, are reported in Table 1. To ensure the changes in test results are due to the built-in ARCH feature, the same set of $x_{\mathrm{t}}$ and $\mathrm{v}_{\mathrm{t}}$ are used to generate the data specified by (2) and (3). Comparing the numbers given in columns 4 and 5, we observe that the ARCH effect severely reduces the empirical power of the F-test. For example, consider the 5 percent test. For the case $\varphi_{1}=0.5$ and $\varphi_{2}=0.2$, an ARCH parameter of $\alpha_{1}=0.75$ can lead to a decrease of empirical power from 96 percent to 61 percent. Moreover, the deterioration in power appears positively related to the strength of the ARCH effect.

The last column in Table 1 reports the rejection percentages when the likelihood ratio test is applied to data generated according to (3). Compared with the standard F-test, the likelihood ratio test incorporating the $\mathrm{ARCH}$ effect clearly demonstrates a better power performance. Again, consider the 5 percent test. For the case $\varphi_{1}=0.5, \varphi_{2}=0.2$, and $\alpha_{1}=0.75$, the likelihood ratio test has an empirical power of 86 percent while the F-test has 61 percent.

Overall, the simulation results illustrate that the standard F-test for causality will experience a significant loss of power in the presence of ARCH effects. One can recoup most of the loss in power by explicitly accounting for the ARCH effect in the testing procedure. The sample size and $\mathrm{ARCH}$ parameter values used in Table 1 are comparable to those in the empirical examples discussed in the following section. Simulation results based on a more extensive set of parameter configurations give inferences similar to those reported in Table $1 .^{4}$ We also conducted an experiment with $\varphi_{2}=0$ and $\alpha_{1} \neq 0$ to investigate the effect of ARCH errors on the size of the standard causality test. Interestingly, we find no significant size distortion in

\footnotetext{
${ }^{4}$ For instance, we also considered cases in which $x_{\mathrm{t}}$ and $\mathrm{v}_{\mathrm{t}}$ have correlation coefficients comparable to those of the output and money growth data used in Section IV. The power estimates are very similar to those in Table 1, and there is no change in the rankings of the power performances.
} 
TABLE 1

Power of Causality Tests

\begin{tabular}{|c|c|c|c|c|c|}
\hline \multirow{2}{*}{\multicolumn{2}{|c|}{ Parameter Value }} & \multirow{3}{*}{$\begin{array}{l}\text { Test Size } \\
0.01\end{array}$} & \multirow{3}{*}{$\begin{array}{l}\text { OLS } \\
\text { F-test } \\
\text { White Noise } \\
99.70\end{array}$} & \multirow{3}{*}{$\begin{array}{l}\text { OLS } \\
\text { F-test } \\
A R C H(1) \\
69.07\end{array}$} & \multirow{3}{*}{$\begin{array}{l}\text { MLE likelihood } \\
\text { ratio test }\end{array}$} \\
\hline & & & & & \\
\hline$\alpha_{0}=1.00$ & $\varphi_{1}=0.5$ & & & & \\
\hline \multirow[t]{8}{*}{$\alpha_{1}=0.75$} & $\varphi_{2}=0.3$ & 0.05 & 99.98 & 86.62 & 99.32 \\
\hline & & 0.10 & 100.00 & 91.96 & 99.69 \\
\hline & $\varphi_{1}=0.5$ & 0.01 & 86.76 & 35.51 & 68.14 \\
\hline & $\varphi_{2}=0.2$ & 0.05 & 96.23 & 60.99 & 86.27 \\
\hline & & 0.10 & 98.37 & 73.08 & 92.07 \\
\hline & $\varphi_{1}=0.5$ & 0.01 & 27.51 & 8.83 & 15.24 \\
\hline & $\varphi_{2}=0.1$ & 0.05 & 54.42 & 25.26 & 33.86 \\
\hline & & 0.10 & 67.84 & 37.85 & 45.64 \\
\hline$\alpha_{0}=1.00$ & $\varphi_{1}=0.5$ & 0.01 & 99.70 & 57.46 & 96.88 \\
\hline \multirow{8}{*}{$\alpha_{1}=0.85$} & $\varphi_{2}=0.3$ & 0.05 & 99.98 & 78.35 & 99.24 \\
\hline & & 0.10 & 100.00 & 86.34 & 99.65 \\
\hline & $\varphi_{1}=0.5$ & 0.01 & 86.76 & 27.80 & 67.20 \\
\hline & $\varphi_{2}=0.2$ & 0.05 & 96.23 & 52.13 & 85.80 \\
\hline & & 0.10 & 98.37 & 64.99 & 91.62 \\
\hline & $\varphi_{1}=0.5$ & 0.01 & 27.51 & 7.01 & 14.90 \\
\hline & $\varphi_{2}=0.1$ & 0.05 & 54.42 & 21.80 & 33.29 \\
\hline & & 0.10 & 67.84 & 33.52 & 45.29 \\
\hline
\end{tabular}

Notes: The results are based on 10,000 simulations with the sample size of 300 . The rejection percentages under column 4 are computed from artificial data generated according to equation (2) and those under columns 5 and 6 are from data generated according to equation (3) in the text. Column 1 gives ARCH parameter values under equation (3). Column 2 gives the parameter values that are common to both equations (2) and (3). $\varphi_{0}=0.00001$ for all cases. Column 3 gives the nominal test size.

the presence of ARCH errors. To conserve space, we did not report the simulation results on the size effect. All these additional simulation results are available upon request.

\section{Money-output Causality}

As pointed out in Section II, the empirical money-output causality regression typically has lagged output (the dependent variable) as one of the regressors. Given the simulation results, we know that it will be difficult to uncover the monetary effect if there is conditional heteroskedasticity. In this section, we re-examine two empirical studies, Friedman and Kuttner (1993) and Thoma (1994), to highlight the potential effect of conditional heteroskedasticity on money-output causality test results. 


\section{Friedman and Kuttner (1993)}

Friedman and Kuttner (1993) extend the analysis of Stock and Watson (1989) by increasing the sample size and using an alternative interest rate variable. The reduced-form equation used to test for monetary effects is (Friedman and Kuttner, 1993, equation 2)

$$
\begin{aligned}
\Delta y_{t}= & c+\mu t+\sum_{i=1}^{12} \gamma_{i} \Delta y_{t-i}+\sum_{i=1}^{6} \lambda_{i} \Delta m_{t-i}+\sum_{i=1}^{12} \delta_{i} \Delta p_{t-i} \\
& +\sum_{i=1}^{12} \theta_{i} \Delta r_{P, t-i}+\sum_{i=1}^{12} \phi_{i}\left(r_{P}-r_{B}\right)_{t-i}+\varepsilon_{t} .
\end{aligned}
$$

The output $\left(y_{\mathrm{t}}\right)$ and money $\left(m_{\mathrm{t}}\right)$ are represented by the industrial production index and M1 in logs, respectively. The vector of control variables ( $w_{\mathrm{t}}$ in (1)) includes the producer price index $\left(p_{\mathrm{t}}\right.$, in logs), the commercial paper rate $\left(r_{\mathrm{p}, \mathrm{t}}\right)$, and the secondary-market three-month U.S. Treasury bill rate $\left(r_{\mathrm{B}, \mathrm{t}}\right)$. The trend term is defined as $f_{\mathrm{t}}=\mathrm{c}+\mu \mathrm{t}, \Delta \equiv(1-\mathrm{L})$ is the first-difference operator, and $\varepsilon_{\mathrm{t}}$ is the error term. Based on the sample period 1959:011990:12 and the F-statistic, Friedman and Kuttner (1993) find the money variables are not jointly significant; that is, money does not affect output. This result is contrary to the one reported in Stock and Watson (1989).

Before testing for the monetary effect, we performed some preliminary data analyses to ensure (4) is an adequate model to work with. First, the ADF-GLS test (Elliot, Rothenberg, and Stock, 1996) results indicated that all of the variables are integrated order of one and the interest rate spread $r_{\mathrm{P}}-r_{\mathrm{B}}$ is stationary. Further, the Johansen (1991) procedure showed that the variables are not cointegrated and, hence, an error correction term is not required in (4). To conserve space, these preliminary test statistics are not reported, but are available from the authors. In terms of the integrating properties of the variables, we consider (4) to be an appropriate specification.

The causality test results are summarized in Table 2. Similar to Friedman and Kuttner (1993), the LS estimation finds no evidence of monetary effects. The F-statistic fails to reject the null hypothesis that effects of lagged money growth are jointly insignificant. However, the $\mathrm{Q}^{2}$-statistics indicate the possibility of ARCH effects. While the residuals are not serially correlated, the squared residuals are.

The results based on the ML estimation of (4) with an $\operatorname{ARCH}(1)$ error structure (that is, $\varepsilon_{\mathrm{t} \mid \mathrm{t}-1} \sim\left(0, \mathrm{~h}_{\mathrm{t}}\right)$ and $\left.\mathrm{h}_{\mathrm{t}}=\alpha_{0}+\alpha_{1} \varepsilon_{\mathrm{t}-1}^{2}\right)$ are presented in the last two columns in Table 2.A. The ARCH parameter $\alpha_{1}$ is highly significant. As indicated by the diagnostics, the ARCH(1) specification adequately describes the conditional heteroskedasticity in (4). On the monetary effect, the likelihood ratio test rejects the hypothesis that the money has no effect on 
future output. Thus, once the ARCH effect is allowed for, the money-output causality documented by Stock and Watson (1989) is actually robust to the extension of the sample period and the use of an alternative measure of the interest rate variable.

Friedman and Kuttner (1993) also report that the commercial paper rate has no impact on future output. As the ARCH effect can obscure the causation relationship between money and output, it may also yield misleading evidence on the effect of commercial paper rates. Thus, we re-examine the commercial paper rate effect and present the results in Table 2.B. Using the LS approach and allowing for no ARCH effects, the F-statistic for the joint significance of commercial paper rate coefficients has a p-value of 35 percent. This confirms the result reported in Friedman and Kuttner (1993). However, when the error term is corrected for ARCH effects, we reject the hypothesis that the coefficients of commercial paper rates are jointly insignif-

TABLE 2

Money-Output Causality - The Friedman and Kuttner (1993) Case

\begin{tabular}{llllll}
\hline 2.A. Money Causes Output & \multicolumn{3}{l}{ ARCH (MLE) } \\
\cline { 2 - 3 } \cline { 5 - 6 } Causality Test & 0.6149 & {$[0.7183]$} & & $14.3286^{*}$ & {$[0.0261]$} \\
\hline ARCH Parameters & & & & & \\
$\alpha_{0}$ & - & - & & $0.000021^{* *}$ & $(0.000003)$ \\
$\alpha_{1}$ & - & - & & $0.749106^{* *}$ & $(0.16294)$ \\
\hline $\mathrm{Q}(1)$ & 0.1609 & {$[0.6882]$} & & 2.6450 & {$[0.1038]$} \\
$\mathrm{Q}(3)$ & 1.9414 & {$[0.5846]$} & & 2.9143 & {$[0.4050]$} \\
$\mathrm{Q}(6)$ & 2.4539 & {$[0.8735]$} & & 3.5800 & {$[0.7333]$} \\
$\mathrm{Q}^{2}(1)$ & $3.1276^{\dagger}$ & {$[0.0769]$} & & 0.0562 & {$[0.8124]$} \\
$\mathrm{Q}^{2}(3)$ & 3.7473 & {$[0.2900]$} & & 0.8537 & {$[0.8365]$} \\
$\mathrm{Q}^{2}(6)$ & 5.6566 & {$[0.4627]$} & & 2.6717 & {$[0.8487]$} \\
\hline
\end{tabular}

2.B. Interest Rates Cause Output

\begin{tabular}{|c|c|c|c|c|}
\hline \multirow[b]{2}{*}{ Causality Test } & \multicolumn{2}{|l|}{$O L S$} & \multicolumn{2}{|c|}{$A R C H(M L E)$} \\
\hline & 1.1149 & [0.3469] & $24.4224^{*}$ & [0.0178] \\
\hline
\end{tabular}

Notes: The least squares regression results of equation (4) are summarized in columns 2 and 3. Columns 4 and 5 give the maximum likelihood estimation results allowing for an $\mathrm{ARCH}(1)$ error term. The numbers in parentheses are the standard errors. P-values are given in square brackets. '**, '*, , and ' $\dagger$ ' denote $1 \%, 5 \%$, and $10 \%$ levels of significance, respectively. The row labeled 'Causality Test' gives the F-statistics and the likelihood ratio statistics for the hypothesis of money does not cause output in panel 2.A and for the hypothesis of commercial paper rates do not cause output in panel 2.B. $\mathrm{Q}(\mathrm{k})$ and $\mathrm{Q}^{2}(\mathrm{k})$ give the Ljung-Box $\mathrm{Q}$-statistics calculated from the first $\mathrm{k}$ autocorrelations of the estimated (standardized) errors and their squares. 
icant. That is, there is evidence of commercial paper rates affecting future output. Again, the result of no-commercial-paper-rate effect may be the consequence of ignoring ARCH effects in the model.

\section{Thoma (1994)}

Thoma (1994) devises a regression equation to test for asymmetries in the effects of positive and negative changes in money growth and the differential effects of money growth over the business cycle. For the sample period of 1959:01-1989:12, Thoma (1994, equation 14) considers

$$
\begin{aligned}
\Delta y_{t}= & c+\mu t+\sum_{i=1}^{12} \gamma_{i} \Delta y_{t-i}+\sum_{i=1}^{6} \lambda_{i}^{+} \Delta m_{t-i}^{+}+\sum_{i=1}^{6} \lambda_{i}^{-} \Delta m_{t-i}^{-} \\
& +\sum_{i=1}^{6} \psi_{i}^{+} S_{t-i} \Delta m_{t-i}^{+}+\sum_{i=1}^{6} \psi_{i}^{-} S_{t-i} \Delta m_{t-i}^{-}+\sum_{i=1}^{12} \delta_{i} \Delta p_{t-i} \\
& +\sum_{i=1}^{12} \theta_{i} \Delta r_{B, t-i}+\varepsilon_{t} .
\end{aligned}
$$

The effects of positive and negative changes in money (M1) growth are captured by $\Delta m_{\mathrm{t}}^{+}$and $\Delta m_{\mathrm{t}}^{-}$, where

$$
\begin{aligned}
\Delta m_{t}^{+} & =\Delta m_{t} \text { if } \Delta \mathrm{m}_{\mathrm{t}}>\Delta \mathrm{m}_{\mathrm{t}-1} \\
& =0 \text { otherwise }
\end{aligned}
$$

and

$$
\begin{aligned}
\Delta m_{t}^{-} & =\Delta m_{t} \text { if } \Delta \mathrm{m}_{\mathrm{t}}<\Delta \mathrm{m}_{\mathrm{t}-1} \\
& =0 \text { otherwise. }
\end{aligned}
$$

The effects of money growth over the business cycle are captured by $\mathrm{S}_{\mathrm{t}-\mathrm{i}} \Delta m_{\mathrm{t}-\mathrm{i}}^{+}$and $S_{\mathrm{t}-\mathrm{i}} \Delta m_{\mathrm{t}-\mathrm{i}}^{-}$, where $S_{\mathrm{t}}$ is a proxy for the state of the economy and is measured by the deviation of the output growth from a linear time trend. Other variables in (5) are the same as those defined for (4). ${ }^{5}$ Again, the

\footnotetext{
${ }^{5}$ Thoma (1994) states that the consumer price index (CPI) is used. However, the ADF-GLS test suggests the CPI data have two unit roots. Further, we cannot replicate Thoma's results using the CPI data. On the other hand, the producer price index (PPI) data yield results that are very similar to those reported in Thoma (1994) and have only one unit root. Thus, PPI data are used in the subsequent analysis.
} 
unit root and cointegration tests (results not reported) indicate that (5) is an appropriate specification.

The test results are reported in Table 3. Using the standard F-test, we are able to reject the hypothesis of $\lambda_{\mathrm{i}}^{-}=\psi_{\mathrm{i}}^{-}=0$ but not the one of $\lambda_{\mathrm{i}}^{+}=$ $\psi_{i}^{+}=0$ for $i=1, \ldots, 6$. That is, negative monetary shocks, but not positive ones, affect future output growth. The result is consistent with Thoma's findings. However, the diagnostics suggest evidence of ARCH effects. The ML estimation of (5) with an ARCH(1) error confirms the presence of ARCH effects. An ARCH(1) coefficient of 0.88 provides an adequate description of the conditional heteroskedasticity in the error term. The likelihood ratio test rejects the hypothesis of $\lambda_{i}^{+}=\psi_{i}^{+}=0$. Thus, when the conditional heteroskedasticity in the disturbance term is accounted for, we have evidence of positive monetary shocks affecting future output. This result is contrary to the prediction of the price downward rigidity argument.

\section{Magnitude of the Monetary Effect}

The preceding exercises show that ignoring conditional volatility can lead to erroneous statistical inferences on the effect of money on output. The ML approach, which yields efficient estimates, indicates that output is affected by money. The importance of money, however, depends on both the joint statistical significance of the lagged money variables and the magnitude of the monetary effect. In fact, Sims (1980) advises the use of forecast error variance decomposition analysis, in addition to statistical significance, to evaluate the causal effect. To gain further insight into the monetary effect, we compare the forecast error variance decomposition results from the LS and ARCH-MLE specifications. ${ }^{6}$

As an illustration, we decompose the output growth forecast error variance using, respectively, the LS and ARCH-MLE estimates of equation (4). ${ }^{7}$ The six-, twelve-, and twenty-four-months forecasting horizons are considered. Following Friedman and Kuttner (1993), the orderings $\left(\Delta y_{\mathrm{t}}, \Delta p_{\mathrm{t}}\right.$, $\left.\Delta m_{\mathrm{t}}, \Delta r_{\mathrm{p}, \mathrm{t}},\left(r_{\mathrm{p}, \mathrm{t}}-r_{\mathrm{B}, \mathrm{t}}\right)\right)$ and $\left(\Delta y_{\mathrm{t}}, \Delta p_{\mathrm{t}},\left(r_{\mathrm{p}, \mathrm{t}}-r_{\mathrm{B}, \mathrm{t}}\right), \Delta r_{\mathrm{p}, \mathrm{t}}, \Delta m_{\mathrm{t}}\right)$ are examined. The proportions of output growth forecast error variances attributable to the money and interest rate variables are given in Table 4. For both types of orderings, the results based on the LS estimates tend to understate money's

\footnotetext{
${ }^{6}$ As reported in Granger, Robins, and Engle (1984), coefficient estimates from the LS and ARCH-MLE procedures can be quite different. Thus, the two sets of estimates can give dissimilar forecast error variance decomposition results.

${ }^{7}$ Equation (5) is not considered since four variables derived from money growth are included as regressors. Further, Thoma (1994) examines only the output equation. Also, for simplicity, we assume there are no cross-equation $\mathrm{ARCH}$ interactions between individual equations.
} 
TABLE 3

Money-Output Causality - The Thoma (1994) Case

\begin{tabular}{|c|c|c|c|c|}
\hline \multirow[b]{2}{*}{ Causality Test } & \multicolumn{2}{|l|}{$O L S$} & \multicolumn{2}{|c|}{$A R C H(M L E)$} \\
\hline & 1.5378 & {$[0.1096]$} & $25.6249^{*}$ & {$[0.0121]$} \\
\hline \multicolumn{5}{|c|}{ ARCH Parameters } \\
\hline$\alpha_{0}$ & - & - & $0.00002^{* *}$ & $(0.000003)$ \\
\hline$\alpha_{1}$ & - & - & $0.8840^{* *}$ & $(0.1958)$ \\
\hline $\mathrm{Q}(1)$ & 0.0597 & {$[0.8068]$} & 2.0451 & {$[0.1526]$} \\
\hline $\mathrm{Q}(3)$ & 2.5034 & {$[0.4746]$} & 3.1165 & {$[0.3740]$} \\
\hline $\mathrm{Q}(6)$ & 2.8721 & {$[0.8247]$} & 4.3359 & {$[0.6313]$} \\
\hline $\mathrm{Q}^{2}(1)$ & $4.5552^{*}$ & {$[0.0328]$} & 0.5848 & {$[0.4444]$} \\
\hline$Q^{2}(3)$ & 5.9587 & {$[0.1136]$} & 1.0387 & [0.7918] \\
\hline$Q^{2}(6)$ & 7.3346 & {$[0.2910]$} & 1.8174 & {$[0.9357]$} \\
\hline
\end{tabular}

Notes: The least squares regression results of equation (5) are summarized in columns 2 and 3. Columns 4 and 5 give the maximum likelihood estimation results allowing for an $\mathrm{ARCH}(1)$ error term. The numbers in parentheses are the standard errors. P-values are given in square brackets. '**, and '*', denote $1 \%$ and $5 \%$, levels of significance, respectively. The row labeled 'Causality Test' gives the F-statistics and the likelihood ratio statistics for the hypothesis of 'positive' money shocks do not cause output. $\mathrm{Q}(\mathrm{k})$ and $\mathrm{Q}^{2}(\mathrm{k})$ give the Ljung-Box Q-statistics calculated from the first $\mathrm{k}$ autocorrelations of the estimated (standardized) errors and their squares.

contribution to unexpected output variability. ${ }^{8}$ The problem of underestimation apparently is more severe at short horizons than at long horizons. Besides precision, controlling for ARCH effects can have implications for the magnitude of the monetary effect. However, it should be noted that the ARCH-MLE procedure does not necessarily increase the magnitude of the causality effect.

In this example, the use of the ARCH-MLE method reveals the statistical significance of money and increases the measured monetary effect. The overall evidence on the importance of money, however, is quite limited. Indeed, for the estimation methods and variable orderings examined, less than 1.5 percent of the output forecast error variance is explained by money. The interest rate variables, compared with the money variable, explain a larger fraction of output uncertainty. ${ }^{9}$ Thus, while money is statistically significant after accounting for conditional volatility, it is unlikely to be a principal source of output fluctuations.

\footnotetext{
${ }^{8}$ The results based on the LS procedure are consistent with those in Friedman and Kuttner (1993).

${ }^{9}$ In contrast with the money effect, the adjustment for ARCH effects lowers the magnitudes of the two interest-rate effects. The results are in accordance with the conjecture that ARCH-adjustment can lead to increase or decrease in the measured magnitude of causality.
} 
TABLE 4

Forecast Error Variance Decomposition

\begin{tabular}{lcccc}
\hline & & \multicolumn{3}{l}{ Percentage of Output Variances Explained by } \\
\cline { 2 - 5 } $\begin{array}{l}\text { Estimation } \\
\text { Method }\end{array}$ & $\begin{array}{l}\text { Forecast Horizons } \\
\text { in Months }\end{array}$ & $\Delta m_{\mathrm{t}}$ & $\Delta r_{\mathrm{p}, \mathrm{t}}$ & $\left(r_{\mathrm{p}, \mathrm{t}}-r_{\mathrm{B}, \mathrm{t}}\right)$ \\
\hline A. Ordering: $\left(\Delta y_{\mathrm{t}}, \Delta p_{\mathrm{t}}, \Delta m_{\mathrm{t}}, \Delta r_{\mathrm{p}, \mathrm{t}},\left(r_{\mathrm{p}, \mathrm{t}}-r_{\mathrm{B}, \mathrm{t}}\right)\right)$ & & \\
OLS & 6 & 0.673 & 8.631 & 5.703 \\
& 12 & 0.615 & 12.058 & 7.938 \\
& 24 & 1.206 & 13.442 & 8.574 \\
ARCH-MLE & 6 & 0.935 & 10.088 & 3.958 \\
& 12 & 1.051 & 11.046 & 4.587 \\
& 24 & 1.261 & 13.136 & 6.192 \\
B. Ordering: $\left(\Delta y_{\mathrm{t}}, \Delta p_{\mathrm{t}},\left(r_{\mathrm{p}, \mathrm{t}}-r_{\mathrm{B}, \mathrm{t}}\right), \Delta r_{\mathrm{p}, \mathrm{t}}, \Delta m_{\mathrm{t}}\right)$ & & \\
OLS & 6 & 0.439 & 4.560 & 10.009 \\
& 12 & 0.407 & 6.098 & 14.106 \\
ARCH-MLE & 24 & 0.929 & 7.470 & 14.823 \\
& 6 & 0.988 & 6.278 & 7.714 \\
& 12 & 1.087 & 7.650 & 7.947 \\
& 24 & 1.323 & 9.017 & 10.249 \\
\hline
\end{tabular}

Notes: The entries in the third to fifth columns are the percentages of output forecast error variances explained by the money $\left(\Delta m_{\mathrm{t}}\right)$ and interest rates $\left(\Delta r_{\mathrm{p}, \mathrm{t}}, r_{\mathrm{p}, \mathrm{t}}-r_{\mathrm{B}, \mathrm{t}}\right)$ variables. The estimation methods (OLS and ARCH-MLE) used to generate the parameters in equation (4) for the forecast error variance decomposition analysis and the forecast horizons are given in columns 1 and 2 .

\section{Concluding Remarks}

The effect of money and the way money affects output are crucial to the understanding of the role of monetary policy and business cycles. An enormous amount of literature is devoted to studying the monetary effect. As discussed in the introduction, there are both theoretical and empirical motivations for including ARCH effects in examining the influence of money on aggregate output. Most empirical exercises in this literature, however, do not consider ARCH effects. Using Monte Carlo methods, it is illustrated that the presence of ARCH effects can substantially lower the power of the conventional causality test and mislead researchers to conclude a variable does not influence the future path of another variable.

In re-examining two money-output causality regressions, we identify the presence of ARCH effects. We further show that the no-money-effect results are reported because the original studies ignore the ARCH effect. The two empirical examples highlight the possibility of the presence of conditional heteroskedasticity in a typical money-output causality regression and its implications for statistical inference. When the ARCH effect is not appro- 
priately modeled, we may obtain erroneous inferences on the statistical significance and the magnitude of the monetary effect. Thus, a proper test of models for money-output causality should allow for ARCH effects.

To be fair, we do not mean to implicate previous studies and claim that they are all subject to the ARCH effect criticism. Rather, we would like to point out the potential cost of ignoring ARCH effects in conducting moneyoutput causality analysis.

Date of Receipt of Final Manuscript: December 2000.

\section{References}

Barro, R. J. (1977). 'Unanticipated Money Growth and Unemployment in the United States', American Economic Review, Vol. 67, pp. 101-115.

Bernanke, B. S. and Mihov, I. (1998). 'Measuring Monetary Policy', Quarterly Journal of Economics, Vol. 13, pp. 869-902.

Blanchard, O. J. (1990). 'Why Does Money Affect Output? A Survey', in Friedman, M. and Hahn, F. H. (eds.), Handbook of Monetary Economics, Vol. 2, North-Holland, Amsterdam.

Christiano, L. and Ljungqvist, L. (1988). 'Money Does Granger-Cause Output in the Bivariate Money-Output Relation', Journal of Monetary Economics, Vol. 22, pp. 217-36.

Cochrane, J. H. (1998). 'What Do the VARs Mean? Measuring the Output Effects of Monetary Policy', Journal of Monetary Economics, Vol. 41, pp. 277-300.

Cover, J. P. (1992). 'Asymmetric Effects of Positive and Negative Money-Supply Shocks', Quarterly Journal of Economics, Vol. 4, pp. 1261-282.

Elliott, G., Rothenberg, T. J. and Stock, J. H. (1996). 'Efficient Tests for an Autoregressive Unit Root', Econometrica, Vol. 64, pp. 813-36.

Engle, R. F. (1982). 'Autoregressive Conditional Heteroskedasticity with Estimates of the Variance of UK Inflation', Econometrica, Vol. 50, pp. 987-1008.

Faust, J. (1998). 'The Robustness of Identified VAR Conclusions about Money', International Finance Discussion Papers 1998-610, Board of Governors of the Federal Reserve System.

Friedman, B. M. and Kuttner, K. N. (1992). 'Money, Income, Prices, and Interest Rates', American Economic Review, Vol. 82, pp. 472-492.

Friedman, B. M. and Kuttner, K. N. (1993). 'Another Look at the Evidence on Money-Income Causality', Journal of Econometrics, Vol. 57, pp. 189-203.

Friedman, M. and Schwartz, A. (1963). A Monetary History of the United States, Princeton University Press, Princeton.

Galbraith, J. W. (1996). 'Credit Rationing and Threshold Effects in the Relation between Money and Output', Journal of Applied Econometrics, Vol. 11, pp. 419-29.

Granger, C. W. J. (1980). 'Testing for Causality - A Personal Viewpoint', Journal of Economic Dynamic and Control, Vol. 2, pp. 329-52.

Granger, C. W. J., Robins, R. P. and Engle, R. F. (1984). 'Wholesale and Retail Prices: Bivariate Time Series Modeling with Forecastable Error Variances', in Besley, D. and Kuh, E. (eds.), Model Reliability, MIT Press, Cambridge.

Grier, K. B. and Perry, M. J. (1993). 'The Effect of Monetary Shocks on Interest Rates in the Presence of Conditional Heteroskedasticity', Journal of Finance, Vol. 48, pp. 1445-455.

Johansen, S. (1991). 'Estimation and Hypothesis Testing of Cointegration Vectors in Gaussian Vector Autoregressive Models', Econometrica, Vol. 59, pp. 1551-580. 
Krol, R. and Ohanian, L. E. (1990). 'The Impact of Stochastic and Deterministic Trends on Money-Output Causality: A Multy-Country Investigation', Journal of Econometrics, Vol. 45, pp. 291-308.

Litterman, R. and Weiss, L. (1985). 'Money, Real Interest Rates, and Output: A Reinterpretation of Postwar U.S. Data', Econometrica, Vol. 53, pp. 129-56.

Lucas, R. E. Jr. (1972). 'Expectations and the Neutrality of Money', Journal of Economic Theory, Vol. 4, pp. 103-24.

Lucas, R. E. Jr. (1996). 'Nobel Lecture: Monetary Neutrality', Journal of Political Economy, Vol. 104, pp. 661-82.

Ravn, M. O. and Sola, M. (1996). 'A Reconsideration of the Empirical Evidence on the Asymmetric Effects of Money-Supply Shocks: Positive vs. Negative or Big vs. Small?', Centre for Non-linear Modeling in Economics Working Paper No. 1996-4, University of Aarhus.

Rhee, W. and Rich, R. W. (1995). 'Inflation and the Asymmetric Effects of Money on Output Fluctuations', Journal of Macroeconomics, Vol. 17, pp. 683-702.

Sargent, T. (1996). 'Expectations and the Nonneutrality of Lucas', Journal of Monetary Economics, Vol. 37, pp. 535-48.

Sims, C. A. (1972). 'Money, Income, and Causality', American Economic Review, Vol. 62, pp. $540-52$.

Sims, C. A. (1980). 'Macroeconomics and Reality', Econometrica, Vol. 48, pp. 1-48.

Sims, C. A. (1992). 'Interpreting the Macroeconomic Time Series Facts: the Effects of Monetary Policy', European Economic Review, Vol. 36, pp. 975-1000.

Stock, J. H. (1988). 'Estimating Continuous Time Process Subject to Time Deformation', Journal of the American Statistical Association, Vol. 83, pp. 77-85.

Stock, J. H. and Watson, M. W. (1989). 'Interpreting the Evidence on Money-Income Causality', Journal of Econometrics, Vol. 40, pp. 161-81.

Taylor, J. B. (1975). 'Monetary Policy during a Transition to Rational Expectations', Journal of Political Economy, Vol. 83, pp. 1009-1022.

Thoma, M. A. (1994). 'Subsample Instability and Asymmetrics in Money-Income Causality', Journal of Econometrics, Vol. 64, pp. 279-306. 